\title{
La photographie algérienne : de la genèse à la représentation. Introduction
}

Rym Khene

\section{(2) OpenEdition}

\section{Journals}

Édition électronique

URL : https://journals.openedition.org/coma/5557

DOI : 10.4000/coma.5557

ISSN : 2275-1742

Éditeur

Institut des textes \& manuscrits modernes (ITEM)

Référence électronique

Rym Khene, «La photographie algérienne : de la genèse à la représentation. Introduction », Continents manuscrits [En ligne], 14 | 2020, mis en ligne le 15 mai 2020, consulté le 12 janvier 2023. URL : http:// journals.openedition.org/coma/5557 ; DOI : https://doi.org/10.4000/coma.5557

Ce document a été généré automatiquement le 12 janvier 2023.

\section{(c) (i) $\Theta$}

Creative Commons - Attribution - Pas d'Utilisation Commerciale - Pas de Modification 4.0 International - CC BY-NC-ND 4.0

https://creativecommons.org/licenses/by-nc-nd/4.0/ 


\title{
La photographie algérienne : de la genèse à la représentation. Introduction
}

\author{
Rym Khene
}

1 L'idée de consacrer un numéro de Continents Manuscrits à la photographie algérienne est née il y a un an et demi environ. Nous avions alors décidé de questionner la place de la photographie en Algérie, en croisant pratiques photographiques d'artistes et usage des archives photographiques. Notre volonté était de bâtir un numéro interdisciplinaire qui invite chercheurs et artistes à réfléchir ensemble au rôle de la photographie en Algérie.

Entretemps, l'Algérie a connu de grands bouleversements. Avec, durant plus d'un an, le déferlement pacifique de millions d'Algériennes et d'Algériens dans toutes les villes du pays, la révolution du 22 février 2019 a transformé le paysage politique. Elle a aussi donné lieu à l'émergence d'une nouvelle esthétique dans la société.

Depuis le 22 février 2019, la pratique photographique fait événement. Mais si celle-ci acquiert cette dimension nouvelle dans le paysage politique et culturel actuel, c'est aussi parce qu'à l'unisson de l'évolution historique de la société, elle se nourrit d'une tradition déjà ancienne qui s'est particulièrement affirmée pendant la guerre de libération nationale.

Marie Chominot, historienne et commissaire d'expositions, nous emmène à la recherche des archives Mohamed Kouaci, photographe attitré du GPRA (Gouvernement Provisoire de la République Algérienne), et l'une des figures principales de la médiatisation du combat pour l'indépendance.

Fadila Yahou, doctorante en Histoire de l'art (Université Paris I Sorbonne), explore le fonds photographique de Paris Match et analyse la construction visuelle de la guerre d'indépendance algérienne (1954-1962) que le magazine opère.

Par une approche ethnographique, Awel Haouati, doctorante en anthropologie à l'EHESS (École des Hautes Études en Sciences Sociales), étudie la trajectoire de photographies de presse des années 1990 pour faire émerger des « images latentes » à interroger aujourd'hui. 
Le projet Memory of Violence de Sofiane Zouggar est un travail sur l'image et la violence des années 1990. C'est ici l'occasion de suivre le geste archivistique de l'artiste.

Dans ce numéro figurent également, des «expériences photographiques» de photographes, d'écrivains et de journalistes. L'acte photographique se mue en acte politique, la photo que l'on rate, l'image manquante, ou encore le désir de tout archiver.

Sabri Benalycherif fait part de la solitude du photographe qui, grâce au mouvement révolutionnaire, découvre un peuple «jusqu'ici imaginé ».

Saïd Djaafer, quant à lui, se demande comment il a pu "rater» une photo. Faire l'expérience de la révolution peut conduire, comme ici, à l'impossibilité d'en capturer certaines images.

Sid Ahmed Semiane marche dans la ville - et dans la mémoire -, dans un texte poignant à la recherche de l'image manquante du récit national.

Halim Zenati nous livre un aperçu de ses photographies algéroises. De 1979 à 2020, vingt photographies qui sont autant de portraits de la ville.

Fatima Chafaa raconte sa quête des archives familiales pour faire le lien entre deux générations, deux histoires qui retrouvent leur chemin, « loin des murs ».

Le Collective220 pose un regard rétrospectif sur son parcours et sa pratique de la photographie ainsi que sur les défis à relever dans le paysage visuel algérien actuel.

Une conversation avec Nabil Djedouani a été l'occasion de montrer le travail du réalisateur et chercheur indépendant qui, à travers des plateformes numériques, valorise le patrimoine cinématographique algérien et réhabilite des images et des figures peu accessibles au public.

Par son approche interdisciplinaire, ce numéro de Continents Manuscrits réunit donc chercheurs, écrivains et photographes qui donnent à voir une réalité de la photographie algérienne : expressive et complexe.

Enfin, une absence.

La disparition brutale de Nasser Medjkane crée un grand vide. Le photographe laisse derrière lui une œuvre importante, par sa beauté, son humanité et sa poésie.

Lors de nos déambulations dans les rues d'Alger, nos conversations ne s'éloignaient jamais trop de la photographie. Le cadre, la contre-plongée, le hors-champ, et tout ce que le photographe voit et construit avant même d'appuyer sur le déclencheur, étaient sa manière de regarder le monde. Nous marchions et je le voyais saisir par le regard des images bleues de portes en bois, de rires d'enfants, et de murs marqués par le temps.

Ce numéro est aussi pour lui. 


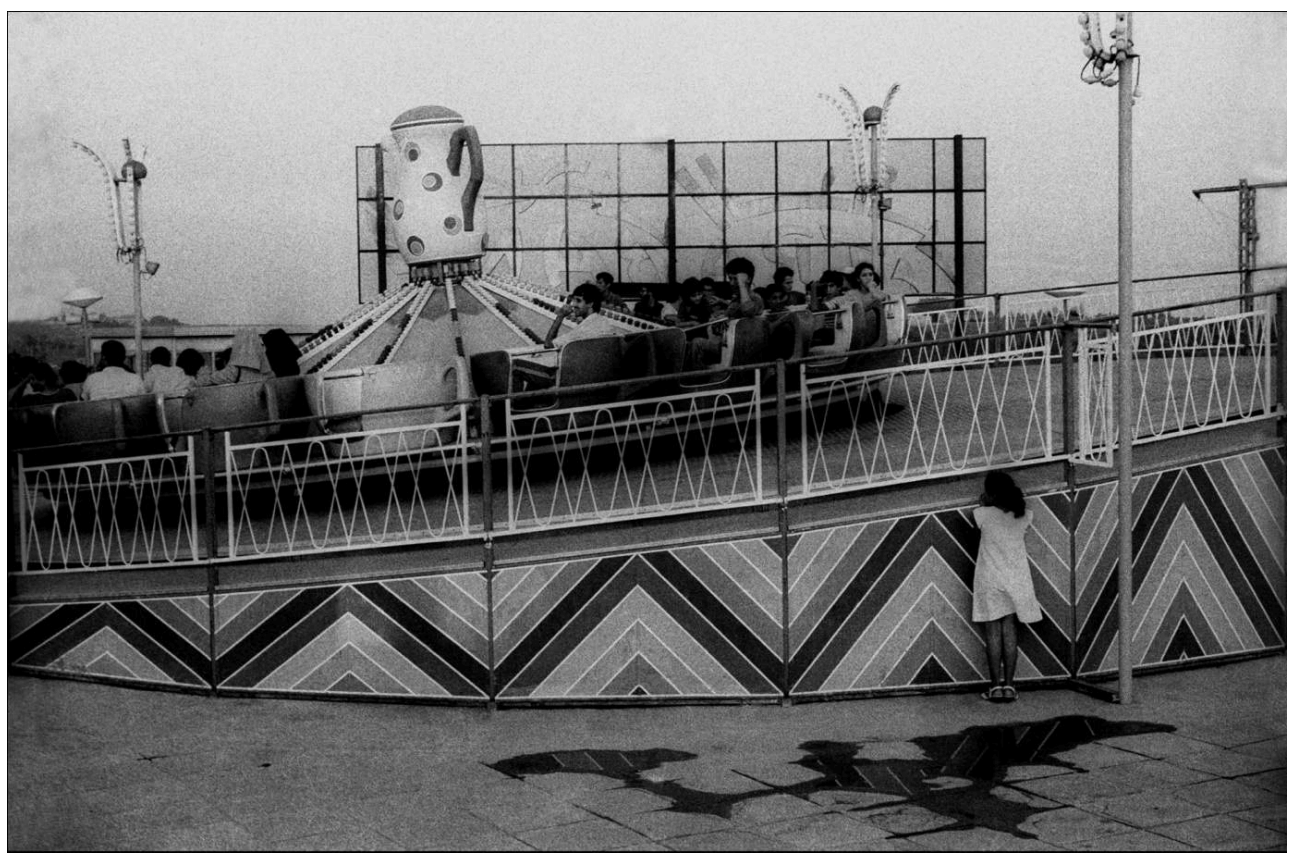

Nasser Medjkane, Alger, 1985

(c) Nasser Medjkane - Fonds privé. Reproduit avec l'aimable autorisation de Meriem Medjkane.

\section{INDEX}

\section{Index géographique : Algérie}

Keywords : Algeria, Algeria 1990s, war, conflict, violence, photography, photojournalism, archives, press, past in the present

Mots-clés : Algérie, années 1990, guerre, conflit, violence, photographie, photojournalisme, archives, presse, passé dans le présent

\section{AUTEUR}

\section{RYM KHENE}

RYM KHENE est doctorante en littérature comparée (Thalim - Sorbonne Nouvelle), chercheuse associée à l'équipe Manuscrits Francophones de l'Institut des Textes et Manuscrits (Item, EnsCNRS) et photographe. Ses recherches portent sur les représentations littéraires et photographiques des villes. www.rymkhene.com 